\title{
Phytochemical study, polyphenols determination and evaluation of antioxidant activity of Origanum compactum and Satureja calamintha nepeta from the region of Ouazzane (Morocco)
}

\author{
Mouhcine Hayani 1,*, Nadia Benhlima ${ }^{1}$, Amal Bouzoubaa ${ }^{1}$, Atika Ailli ${ }^{1}$, Aman Allah Gourich ${ }^{1}$, Aicha \\ Mouradi ${ }^{1}$, Hamid Oulhaj ${ }^{1}$ and Touriya Zair ${ }^{1, *}$ \\ Research team: Chemistry of Bioactive Molecules and Environment, Faculty of Sciences, Moulay Ismail \\ University of Meknes, B.P. 11201, Zitoune, Meknès, 50 000, Morocco
}

\begin{abstract}
Among natural remedies, aromatic and medicinal plants constitute an essential source that deserves scientific attention. Thus, our study aims to promote the virtues of two aromatic and medicinal plants found in the wild in the region of Ouazzane (Morocco). The phytochemical tests of these species have shown the presence of flavonoids, gallic and catechic tannins, cyanidin, sterols and triterpenes. However, alkaloids, carotenoids, saponosides and reducing compounds were not detected. Then, extraction of total polyphenols from Origanum compactum and Satureja calamintha nepeta was conducted for 48 hours by maceration with a mixture of methanol/water (80/20) used as a solvent. Extractions yielded $35.2 \%$ crude extracts for Origanum compactum and $34.4 \%$ for Satureja calamintha nepeta. The fractionation of these crude methanol extracts was performed with three organic solvents of increasing polarity (chloroform, ethyl acetate then, $\mathrm{n}$-butanol). Total phenol content of the extracts and fractions was assessed by the method of Folin-Ciocalteu. This revealed that the phenol-rich fractions were the crude extract for Origanum compactum and the butanol fraction for Satureja calamintha nepeta. Finally, the evaluation of the antioxidant power which was carried out using the method of trapping the free radical $\mathrm{DPPH} \bullet$ and the reduction of iron by the method of FRAP. The DPPH • test showed a high antioxidant activity of the samples: $53.1 \mu \mathrm{g} / \mathrm{ml}$ of crude extract of Origanum compactum was needed to reduce $50 \%$ of DPPH•. The same $\mathrm{IC}_{50}$ was obtained for ascorbic acid (standard antioxidant). For Satureja calamintha nepeta, the $\mathrm{IC}_{50}$ was 67.5 $\mu \mathrm{g} / \mathrm{ml}$. On the other hand, the FRAP test revealed that the methanolic extract of origanum compactum has higher reducing power than that of n-buthanolic extract of satureja calamintha nepeta. Still, it remains relatively low compared to ascorbic acid. The high antioxidant activity of these two species could justify their use in traditional medicine for the treatment of many diseases.
\end{abstract}

Keywords: Medicinal plants; Origanum compactum; Satureja calamintha nepeta; phytochemical study; polyphenol; antioxidant activity; Ouazzane.

\section{Introduction}

Medicinal plants have always been an essential source of medicines. They continue to significantly meet people's need despite the growing influence of the modern health system. Moreover, plants are being sought as sources of natural antioxidants since the use of synthetic antioxidants is currently being questioned because of their potential toxicological risks ${ }^{1,2}$.

Besides, the interest for medicinal plants is supported by their therapeutic properties that are due to hundreds or thousands active ingredients contained therein. These bioactive compounds predominantly belong to secondary metabolites such as polyphenols, components of essential oils and alkaloids ${ }^{3}$. Their role as natural antioxidants is attracting more interest in research areas related to the prevention and the treatment of cancer, inflammatory and cardiovascular diseases ${ }^{4}$.

In this context, we worked on the valorization of extracts from two medicinal plants Origanum compactum, and Satureja calamintha nepeta grow naturally in Ouazzane region (Morocco). Both species belong to the Lamiaceae family which encompasses about 210 genera and 4000 species of dicots ${ }^{5}$.

In Morocco, both species could be found in the middle atlas, the rif and the Atlantic side of the country and can be recognized by their botanical features. Origanum compactum is a perennial plant (30 to $80 \mathrm{~cm}$ ) with ovate-ovoid, hairy leaves attached to pubescent hairy stems. The purple inflorescences are structured in dense and short spikes. The floral bracts are oval-lanceolate rigid and leathery. They 
protect a large flower that consists of 5-sepal ciliated calyces and 5-petal corollas. Origanum compactum is used against colds, flu, ENT disorders and bronchitis. It is also used against mouth sores and inflammation (mouth ulcers and gingivitis) ${ }^{6}$.

Satureja calamintha Nepeta is also a perennial plant (40 cm- height). It exhibits soft and hairy stems that carry opposite and slightly serrated leaves attached with the medium petiole. Its menthol scent can also recognize the species. It is widely popular in Morocco as a remedy for coughs, flatulence, indigestion, and mild respiratory infections. This plant has antiseptic, antispasmodic and carminative properties ${ }^{7}$.

We are interested in the study of the species Satureja calamintha nepeta which is very appreciated in Morocco as a remedy and which grows spontaneously in the region of Ouazzane (masmouda). This very abundant species in this mountainous region ${ }^{7}$ and used frequently by the local population. During our ethnobotanical ${ }^{8}$ survey, we noticed that the local population uses satureja calamintha nepeta as a medicinal plant to treat indigestion and mild respiratory tract infections. This plant has antiseptic, antispasmodic and carminative properties ${ }^{9}$.

Previous studies on the Lamiaceae have shown their richness in a vast range of compounds such as terpenoids, phenolics and flavonoids ${ }^{10}$. We also have performed a phytochemical investigation of the species from Ouazzane which were not yet studied. We have conducted the quantification of phenolic contents in Origanum compactum and Satureja calamintha Nepeta extracts. For this, we are interested in the phytochemical study and the quantification of the contents in phenolic compounds of the extracts of origanum compactum and Satureja calamintha nepeta and the evaluation of their antioxidant power by the method of DPPH• and FRAP as a contribution to finding efficient antioxidant from natural sources.

\section{Material and methods}

\subsection{Plant material: species selection}

As a contribution to the valorization of Ouazzane plant biodiversity, we have studied two species: Origanum Compactum and Satureja calamintha Nepeta (Lamiaceae) 11,12. This choice was based on information that we have gathered through bibliographic work. It also relies on the results of our previous ethnobotanical survey with the local population on plant uses in traditional medicine (the traditional use in the treatment of diseases) ${ }^{11}$. The abundance of the species in the region was also taken into account.

\subsection{Harvesting, geographical location, identification and conservation:}

Origanum compactum and Satureja calamintha nepeta were manually collected in June 2015 in Ouazzane, precisely in Masmouda area, Morocco.
This area is well known for its abundance of aromatic and medicinal plants.

Ouazzane is a city of approximately $1861.2 \mathrm{Km}^{2}$. It is located in the Moroccan north-west (Latitude $34^{\circ} 48$ ' 36 " $\mathrm{N}$ and Longitude $54^{\circ} 43$ '48 "W). It is situated between the rugged hills of the pre-Rif and the agricultural plain of Gharb. The Loukous river limits the South-west of the region. Ouazzane territory is subdivided into several zones, namely: Masmouda, Rhouna, Ghzaoua and Beni Mestara.

Herbaria of both species have been prepared, and then, the species were identified by Professor M. Benattou at the scientific institute of Rabat.

The harvested samples of Origanum Compactum and Satureja calamintha Nepeta were then shade dried at room temperature for fifteen days to preserve as much as possible the integrity of their molecules.

\subsection{Phytochemical study}

\subsection{Determination of water content}

The determination of the water content corresponds to the loss of mass of the sample after heating in an oven at $105 \pm 5^{\circ} \mathrm{C}$ in an isothermal oven ventilated at atmospheric pressure until a constant weight is obtained ${ }^{11}$. The moisture content is calculated according to the following formula:

$\mathrm{TH} \%=\frac{\mathrm{Mf}-\mathrm{Ms}}{\mathrm{Mf}} \times 100$

With:

Mf = mass in $\mathrm{g}$ before the oven

$\mathrm{Ms}=$ mass in $\mathrm{g}$ after the oven

\subsubsection{Phytochemical Screening}

The samples were submitted to phytochemical tests to detect the presence of the leading chemical families of natural compounds. The detection process is called phytochemical screening. It consists in characterization of compounds by complex-forming and staining reactions ${ }^{13,14}$

A specific color is induced by the use of an appropriate reagent in the presence of the proper compound. This is due to the formation of conjugation or an unsaturation within the molecule.

Experimentally, samples of each species are dried and then reduced in a fine powder that is used for the phytochemical tests. Several reagents are also required. The characterization of alkaloids needs Dragendorff's reagent, catechic tannins' characterization requires isoamyl alcohol and hydrochloric acid. Gallic tannins are detected by Stiasny's reagent, sodium acetate and iron (III) chloride. To identify sterols and triterpenes, we used acetic anhydride and concentrated sulfuric acid. For flavonoids, we used dilute hydrochloric acid, magnesium chips and isoamyl alcohol. Chloroform, dilute chlorhydric acid, and ammonium chloride is used to find quinones. 


\subsubsection{Polyphenol extraction}

Polyphenol extraction was performed by maceration. Polyphenol compounds are mainly extracted by solidliquid extraction using a solvent with medium to high polarity ${ }^{13}$. In our study, the solution is prepared with methanol $80 \%$.

An amount of $20 \mathrm{~g}$ of each plant powder was macerated in $200 \mathrm{ml}$ of the solvent (methanol 80\%) for 48 hours. After this period, we proceeded to filtration, and the obtained filtrates were evaporated using a rotary evaporator at $50^{\circ} \mathrm{C}$.

\subsubsection{Fractionation of polyphenol extracts}

Polyphenol extraction depends on the solubility of polyphenolics in organic solvents. Thus, the methanol crude extract was fractionated by the continuous use of three organic solvents of increasing polarity: chloroform, ethyl acetate and n-butanol. This led to the formation four fractions: the hydromethanolic fraction (F0), the chloroform fraction (F1), the ethyl acetate fraction (F2), the butanol fraction (F3) and the aqueous fraction (F4). These fractions were kept until their use. Figure 1 summarizes the fractionation steps of the crude polyphenol extracts. The yield of each extract was determined according to the following formula:

$$
\mathrm{R} \%=\frac{\text { Mass of extract residue }}{\text { Mass of vegetable powder }} \times 100
$$

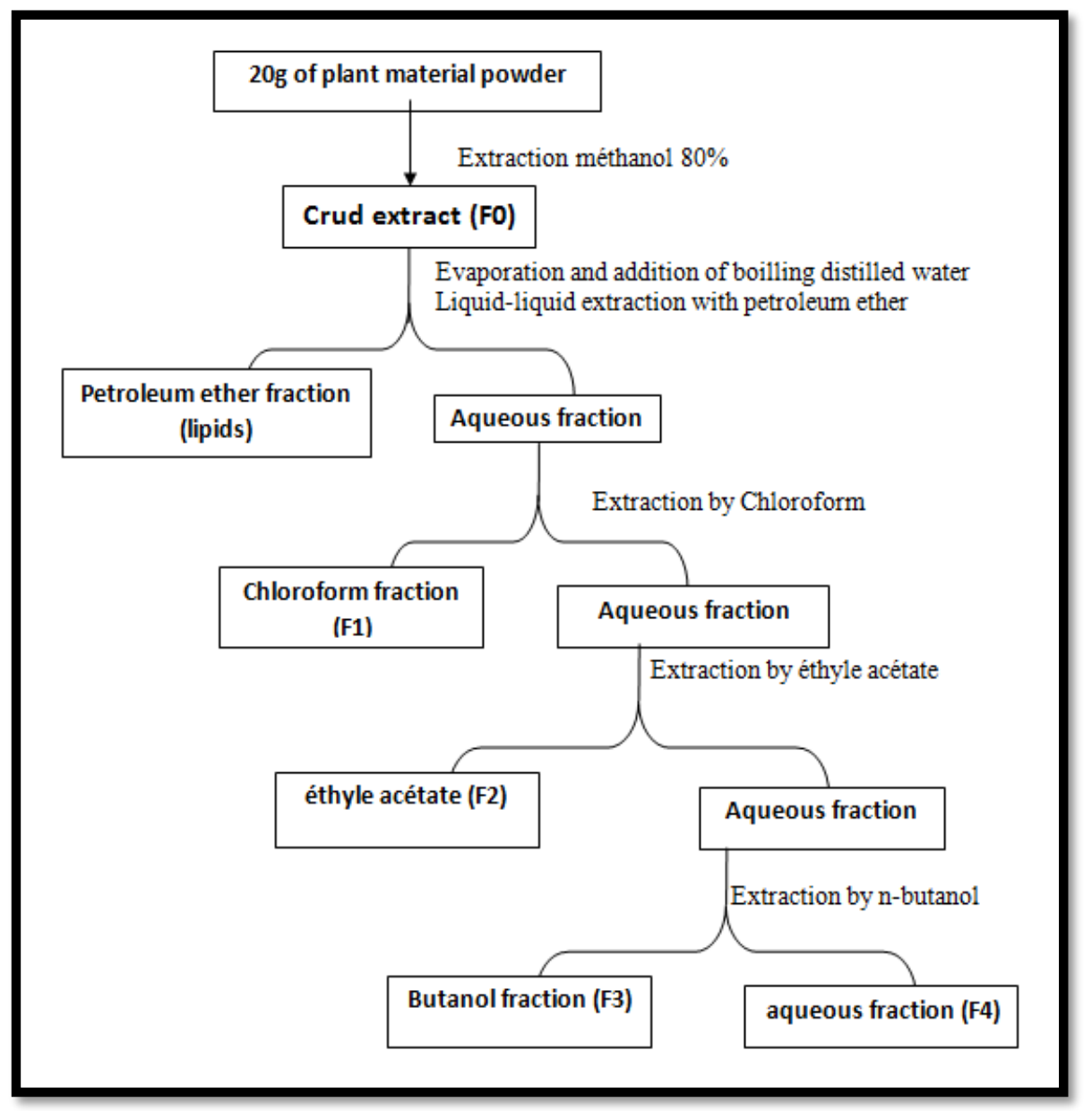

Figure 1. Fractionation process of polyphenols

\subsubsection{Determination of total phenols}

This analysis is an estimate of the total phenol content in the plant fractions. The determination of total phenols was performed by a method adapted from Singleton and Rossi using the Folin-Ciocalteu reagent ${ }^{15-18}$.

In a $100 \mathrm{ml}$ volumetric flask, $100 \mu \mathrm{l}$ of each plant fraction is mixed with $1.5 \mathrm{ml}$ of freshly prepared $10 \%$ Folin-Ciocalteu reagent and $1.5 \mathrm{ml}$ of $7.5 \%$ aqueous sodium carbonate solution $(\mathrm{m} / \mathrm{v})$.
Then, the flasks are supplemented with distilled water. The whole is incubated at room temperature for 30 minutes. The coloration, developed after the incubation period, is proportional to the polyphenol content in the extract and can be quantified by spectrophotometry.

To better assess the polyphenol content in extracts, a calibration curve was established in with gallic acid under the operating conditions and the steps stated above with concentrations ranging from $50 \mu \mathrm{g} / \mathrm{ml}$ $(5 \mathrm{mg} / 100 \mathrm{ml})$. The results are expressed in milligrams 
equivalent of gallic acid per gram of extract (mg GAE $/ \mathrm{g})$. All measurements are repeated thrice.

$\mathrm{T}=\frac{\mathrm{C} \times \mathrm{V}}{\text { m extract }} \times \mathrm{D}$

C: Concentration evaluated according to the calibration curve.

V: Volume of the global extract.

D: Dilution factor with $\mathrm{D}=V f / \mathrm{V} i$

$\mathrm{V} f$ : Final volume to be measured by spectrophotometer

Vi: Volume withdrew from the extract to be tested.

\subsubsection{Determination of total flavonoids}

The quantification of flavonoids was carried out by the colorimetric method ${ }^{19,20}$. From the methanolic solution $(0.1 \mathrm{~g} / \mathrm{L})$ of quercetin, concentration ranges from $5,10,15,20,25$ to $30 \mu \mathrm{g} / \mathrm{ml}$ were prepared in test tubes. Each tube is completed by $3 \mathrm{ml}$ of distilled water. After $5 \mathrm{~min}, 10 \mu \mathrm{l}$ of aluminum trichloride $\left(\mathrm{AlCl}_{3}\right)$ at $10 \%(\mathrm{~m} / \mathrm{v})$ and $2 \mathrm{ml}$ of pure methanol are added, shaken immediately and are kept in the dark for $30 \mathrm{~min}$ at room temperature. The quantitative analysis of flavonoids from our sample extracts was performed using the same protocol used for the calibration curve. The concentration of flavonoids in each extract was calculated from the regression equation of the calibration range established with quercetin. The absorbance was determined at $433 \mathrm{~nm}$ with a Shimadzu UV MINI spectrophotometer. The total flavonoid content was calculated according to the following formula:

$\mathrm{T}=\frac{\mathrm{C} \times \mathrm{V}}{\mathrm{m} \text { extrait }} \times \mathrm{D}$

\subsection{Evaluation of antioxidant activity \\ 2.4.1. DPPH•assay}

Because of its stability and the simplicity of analysis, $\mathrm{DPPH} \bullet$ is a substrate widely used for rapid and direct assessment of the antioxidant activity.

It absorbs at a wavelength of $515 \mathbf{n m}^{2}$ 12,17,21,22. Origanum compactum's crude extract (F0) and the butanolic fraction (F3) of Satureja calamintha nepeta were used to prepare a series of dilution with ethanol to obtain range concentrations from 0 to $200 \mu \mathrm{g} / \mathrm{ml}$. An aliquot of $200 \mu \mathrm{l}$ from each concentration was mixed with $2.8 \mathrm{ml}$ of DPPH in ethanol. Then, after stirring, the tubes were incubated in the dark at room temperature for 30 minutes. The tests were performed with three repetitions for each concentration.

The negative control was prepared by mixing $2.8 \mathrm{ml}$ of $\mathrm{DPPH} \cdot$ solution and $200 \mu \mathrm{l}$ of ethanol. Ascorbic acid, known for its remarkable antioxidant power, is chosen as a positive control. It was used in the same conditions as the test samples. The results were expressed as a percentage of $\mathrm{DPPH} \bullet$ reduction (PI\%).

PI\% = [(Abs control - Abs test $) /$ Abs control $] \times 100$

PI $\%$ : Percentage of antioxidant activity.

Abs control Absorbance of the negative control solution.

Abs test : absorbance of the samples to be tested.

The inhibitory concentration ( $\left.\mathrm{IC}_{50}\right)$ is the concentration of the test sample that reduces $50 \%$ of the $\mathrm{DPPH} \cdot$ radical. It is graphically determined by plotting DPPH• reduction according to the concentrations of test extracts. A low value of $\mathrm{IC}_{50}$ indicates a strong capacity of the extract to reduce $\mathrm{DPPH} \bullet$ radical, thus a strong antioxidant activity.

\subsubsection{FRAP assay}

The FRAP method is based on the reduction reaction of ferric iron $\left(\mathrm{Fe}^{3+)}\right.$ present in the $\mathrm{K}_{3} \mathrm{Fe}(\mathrm{CN})_{6}$ complex to ferrous iron $\left(\mathrm{Fe}^{2+}\right)$ by an antioxidant, the reaction is revealed by transferring the yellow color of ferric iron $\left(\mathrm{Fe}^{3+}\right)$ to the blue-green color of ferrous iron $\left(\mathrm{Fe}^{2+}\right)^{8}$. The test consists of taking $0,5 \mathrm{ml}$ of the phenolic extract at different concentrations $(0,2-1 \mathrm{mg} / \mathrm{ml})$ and mixing them with $1,25 \mathrm{ml}$ of a $0,2 \mathrm{M}$ phosphate buffer solution $(\mathrm{pH}=6,6)$ and $1,25 \mathrm{ml}$ of a potassium ferricyanide solution $\mathrm{K}_{3} \mathrm{Fe}(\mathrm{CN})_{6}$ to $1 \%$. The mixture is incubated at $50^{\circ} \mathrm{C}$ for $20 \mathrm{~min}$ and then cooled to room temperature. Add $2.5 \mathrm{ml}$ of $10 \%$ trichloracetic acid to stop the reaction, after placing the tubes in a centrifuge at $3000 \mathrm{rpm}$ for $10 \mathrm{~min}$. Then add $1.25 \mathrm{ml}$ of the supernatant to $1.25 \mathrm{ml}$ of distilled water and 250 $\mu \mathrm{l}$ of an iron chloride solution $\left(\mathrm{FeCl}_{3}, 6 \mathrm{H}_{2} \mathrm{O}\right)$ to $0.1 \%$. The absorbances are read by spectrophotometry at a wavelength of $700 \mathrm{~nm}$. The positive control is represented by a solution of a standard antioxidant, ascorbic acid. The absorbance of which has been measured under the same conditions as the samples. An increase in absorbance corresponds to an increase in the reducing power of the test extracts.

\section{Results and discussion}

\subsection{Determination of the water content}

The determination of the water content for both species revealed: $18 \%$ for satureja calamintha nepeta and $13.6 \%$ for origanum compactum, which correspond successively in the dry matter to $82 \%$ and $86.4 \%$. The table below shows the species names, the date of harvest, the part used and the percentage of the water content of each plant.

Table 1. water content (\%) of the MAP studied.

\begin{tabular}{|c|c|c|c|}
\hline Name of the plant & harvest date & Part used & Water content (\%) \\
\hline S.calamintha nepeta & May 2015 & Aerial part & 18 \\
\hline O.compactum & May 2015 & Leaves & 13,6 \\
\hline
\end{tabular}


3.2. Phytochemical screening

The phytochemical screening carried out on the plants from the region of Ouazzane, showed the results mentioned in Table 2.

Table 2. Phytochemical screening of Origanum compactum and Satureja calamintha nepeta.

\begin{tabular}{|c|c|c|}
\hline \multirow{2}{*}{ Secondary metabolites } & \multicolumn{2}{|c|}{ Results } \\
\cline { 2 - 3 } Gallic tannins & O. compactum & ++ \\
\hline Catechic tannins & ++ & + \\
\hline Sterols and triterpenes & - & + \\
\hline coumarins & + & - \\
\hline flavonoids & - & ++ \\
\hline alkaloids & ++ & - \\
\hline cyanidins & - & - \\
\hline saponosides & + & - \\
\hline anthocyanins & + & - \\
\hline leucoanthocyanins & - & - \\
\hline
\end{tabular}

$(+)$ : presence; (++): abundance; (-): absence

Phytochemical tests help highlight the presence of the secondary metabolites contained in each plant. In origanum compactum, flavonoids, gallic tannins, cyanidins, sterols and triterpenes and saponosides have been found. Previous work related to the phytochemistry of $O$. vulgare provides similar results of ours with regard to the presence of tannins, saponosides and flavonoids ${ }^{23}$. For satureja calamintha nepeta, the tests showed the presence of flavonoids, gallic tannins, catechin tannins and sterols and triterpenes. But there was no sign of alkaloid, carotenoid and saponoside. These results are similar to several studies ${ }^{12,14}$, and who remarked the presence of the same chemical groups during their phytochemical studies. The presence of these secondary metabolites in the two species studied may explain their strong therapeutic power. It is for this reason that we are convinced that it is necessary to carry out extractions of these compounds to determine their contents and their biological activities ${ }^{13}$. Their role as natural antioxidants is arousing increasing interest in the prevention and treatment of cancer, inflammatory and cardiovascular diseases ${ }^{24}$.

\subsection{Extraction of phenolics}

\subsubsection{Extraction yields}

Methanol extraction of phenolics from Origanum compactum and Satureja calamintha nepeta produced $35.2 \%$ of crude extracts for Origanum compactum and $34.4 \%$ for Satureja calamintha nepeta. After fractionation of these crude extracts with chloroform, ethyl acetate and butanol, the yields were $12.57 \%$ and $17.6 \%$ for n-butanol fractions, $9.05 \%$ and $7.6 \%$ for chloroform fractions, $8.3 \%$ and $4.9 \%$ for the ethyl acetate fractions. The lowest yields were obtained with the aqueous fractions, which were about $5.02 \%$ and $3.2 \%$ for Origanum compactum and satureja calamintha nepeta respectively (Table 3 ). The yields are determined with dry plant matter.

Table 3. Extraction yields of Origanum compactum and satureja calamintha nepeta.

\begin{tabular}{|c|c|c|c|c|c|}
\hline \multirow{2}{*}{ Plant material } & \multicolumn{5}{|c|}{ Extraction yield \% } \\
\cline { 2 - 7 } & $\begin{array}{c}\text { Crude } \\
\text { extract }\end{array}$ & $\begin{array}{c}\text { Chloroform } \\
\text { fraction }\end{array}$ & $\begin{array}{c}\text { Ethyl acetate } \\
\text { fraction }\end{array}$ & $\begin{array}{c}\text { n-butanol } \\
\text { fraction }\end{array}$ & $\begin{array}{c}\text { aqueous } \\
\text { fraction }\end{array}$ \\
\hline O.compactum & 35.2 & 9.05 & 8.3 & 12.57 & 5.02 \\
\hline S.nepeta & 34.4 & 7.6 & 4.9 & 17.6 & 3.2 \\
\hline
\end{tabular}

\subsubsection{Total phenol content}

The UV / Visible spectrophotometry made it possible to quantify the level of polyphenols present in the prepared extracts of the two species studied; the results are expressed in mg equivalent of gallic acid (EAG) per $\mathrm{g}$ of extract in Tables 4 and 5. 
Table 4. Polyphenol contents of Origanum compactum's fractions expressed as milligrams equivalents of gallic acid per gram of extract (mg EAG/g).

\begin{tabular}{|c|c|c|}
\hline & Fractions & Polyphenol content \\
\hline F0 & Crude extract & $\mathbf{3 0 . 8} \pm \mathbf{0 . 0 0 1}$ \\
\hline F1 & Chloroform fraction & $\mathbf{2 0 . 5 3} \pm \mathbf{0 . 0 0 8}$ \\
\hline F2 & Ethyl Acetate fraction & $\mathbf{2 9 . 9} \pm \mathbf{0 . 0 0 7}$ \\
\hline F3 & n- Butanol fraction & $\mathbf{2 8 . 6 3} \pm \mathbf{0 . 0 0 1 5}$ \\
\hline F4 & Aqueous extract & $\mathbf{2 4 . 2 1} \pm \mathbf{0 . 0 4 2}$ \\
\hline
\end{tabular}

Table 5. Polyphenol contents of Satureja calamintha nepeta's fractions expressed as milligrams equivalents of gallic acid per gram of extract (mg EAG / g).

\begin{tabular}{|c|c|c|}
\hline & Fractions & Polyphenol content \\
\hline F0 & Crude extract & $\mathbf{2 5 . 3 6} \pm \mathbf{0 . 0 0 1}$ \\
\hline F1 & Chloroform fraction & $\mathbf{1 5 . 2 6} \pm \mathbf{0 . 0 0 7 5}$ \\
\hline F2 & Ethyl Acetate fraction & $\mathbf{2 7 . 7 9} \pm \mathbf{0 . 0 0 2}$ \\
\hline F3 & n- Butanol fraction & $\mathbf{3 3 . 4 8} \pm \mathbf{0 . 0 2 3 5}$ \\
\hline F4 & Aqueous extract & $\mathbf{2 0 . 4 2} \pm \mathbf{0 . 0 0 4}$ \\
\hline
\end{tabular}

The results show that both plants are rich in polyphenols with total phenol contents for all fractions that vary between $20.53 \pm 0.008 \mathrm{mg} \mathrm{GAE} / \mathrm{g}$ and $30.8 \pm 0.001 \mathrm{mg} \mathrm{GAE} / \mathrm{g}$ for Origanum compactum. These contents vary between $15.26 \pm 0.00752 \mathrm{mg}$ GAE/g and $33.48 \pm 0.0235 \mathrm{mg}$ GAE/g for Satureja calamintha nepeta. The results also revealed that the fractions that contain the highest concentrations of polyphenols are: the crude extract for Origanum compactum (30.8 $\pm 0.001 \mathrm{mg} \mathrm{GAE} / \mathrm{g})$ and the n-butanol fraction for satureja calamintha nepeta (33.48 \pm $0.0235 \mathrm{mg}$ GAE /g). For Satureja calamintha nepeta, our results confirmed the work of Ćetković ${ }^{25}$. In their study, they showed that phenol concentrations in ethyl acetate fraction $(969.43 \mu \mathrm{g} / \mathrm{g})$ and an $n$-butanol fraction $(1358.14 \mu \mathrm{g} / \mathrm{g})$ were significantly higher $(\mathrm{p}<0.001)$ than that of other fraction. Besides, Bougandoura showed in its studies in 2012 that the aqueous extract has a high total phenol content compared to the methanol extract. Other studies ${ }^{25,26}$ has been demonstrated that Origanum compactum's content in polyphenols is higher than that of Origanum glandulosum. Studies have also shown richness in total phenolic content ${ }^{23,27,28}$. These yields can be influenced by several parameters. They also depend on the chemical composition as well as the method and conditions of extraction. Generally, methanol is the most used solvent for the extraction of phenol substances from Lamiaceae.

\subsubsection{Determination of total flavonoids}

A calibration curve was performed with quercetin at a wavelength of $433 \mathrm{~nm}$. The formula for the linear regression of this curve is $\mathrm{y}=0.073 \mathrm{x}-0.081$ with a correlation coefficient $\mathrm{R}^{2}=0.995$. The flavonoid contents of the fractions expressed in mg equivalent of quercetin per $g$ of the dry matter or the extract. The different extracts (crude and fractionated) obtained during the extraction by maceration of the aerial part of satureja calamintha nepeta and the origanum compactum leaves, were quantitatively analyzed by UV-visible spectrophotometer to determine the total flavonoids. The quantitative estimation of flavonoids by the colorimetric method has shown that methanolic extracts are rich. Table 6, shows that satureja calamintha nepeta, contain more flavonoids in terms of methanolic extract $14.71 \pm 0.033 \mathrm{mg} \mathrm{QE} / \mathrm{g}$ and $\mathrm{n}$ butanolic extract $11.55 \pm 0.025 \mathrm{mg} \mathrm{QE} / \mathrm{g}$. In contrast, for origanum compactum the highest content of flavonoids was characterized in terms of methanolic extract with a value of the order of $10.1 \pm 0.045 \mathrm{mg}$ $\mathrm{QE} / \mathrm{g}$.

Table 6. Total flavonoid contents of the origanum compactum and Satureja calamintha Nepeta fractions expressed in milligrams of quercetin equivalents per gram of extract (mg QE / g).

\begin{tabular}{|c|c|c|}
\hline Les fractions & Origanum compactum & Satureja calamintha nepeta \\
\hline crude extract & $10,1 \pm 0,045$ & $14,71 \pm 0,033$ \\
\hline Chloroform extract & $3,90 \pm 0,018$ & $8,29 \pm 0,020$ \\
\hline Ethyl acetate extract & $5,1 \pm 0,020$ & $4,13 \pm 0,013$ \\
\hline Butanolic extract & $2,4 \pm 0,0015$ & $11,55 \pm 0,025$ \\
\hline Aqueous extract & $6,8 \pm 0,022$ & $9,78 \pm 0,028$ \\
\hline
\end{tabular}


The comparison of our results obtained from satureja calamintha nepeta with those of the works of Boughandoura are not similar ${ }^{12}$. Our results are higher than those found by boughandoura in 2012 $(1,280 \mathrm{mg} / \mathrm{g})$, which shows the richness of flavonoids in the Ouazzane region of satureja calamintha nepeta. Other works have proven the richness of oregano in total flavonoids, showed during their study that oregano vulgar is rich in flavonoids. This difference in flavonoid content may be due to several factors such as climate, soil, harvest period, storage condition $^{29}$.

\subsection{Antioxidant activity of the plant extracts}

\subsubsection{DPPH・ test}

The antioxidant activity of Satureja calamintha nepeta and Origanum compactum's extracts was evaluated by spectrophotometery. The ascorbic acid was used as standard antioxidant. In this essay, the most crucial parameter is the kinetics of the DPPH• reduction. This reduction is proved by the solution coloration that changes from purple (DPPH•) to yellow (DPPH-H). This coloration change which is proportional to DPPH reduction is measurable with a spectrophotometer at $515 \mathrm{~nm}^{12,30,31}$.

Results show that Origanum compactum's crude extract ( $\mathrm{F}_{0}$ fraction) and Satureja calamintha nepeta's butanol fraction ( $\mathrm{F}_{3}$ fraction) exerted a very high antioxidant activity with $\mathrm{IC}_{50}$ values equal to 53.1 $\mu \mathrm{g} / \mathrm{ml}$ and $67.5 \mu \mathrm{g} / \mathrm{ml}$ for Origanum compactum and Satureja calamintha nepeta respectively. The $\mathrm{IC}_{50}$ of ascorbic acid is $53.1 \mu \mathrm{g} / \mathrm{ml}$.

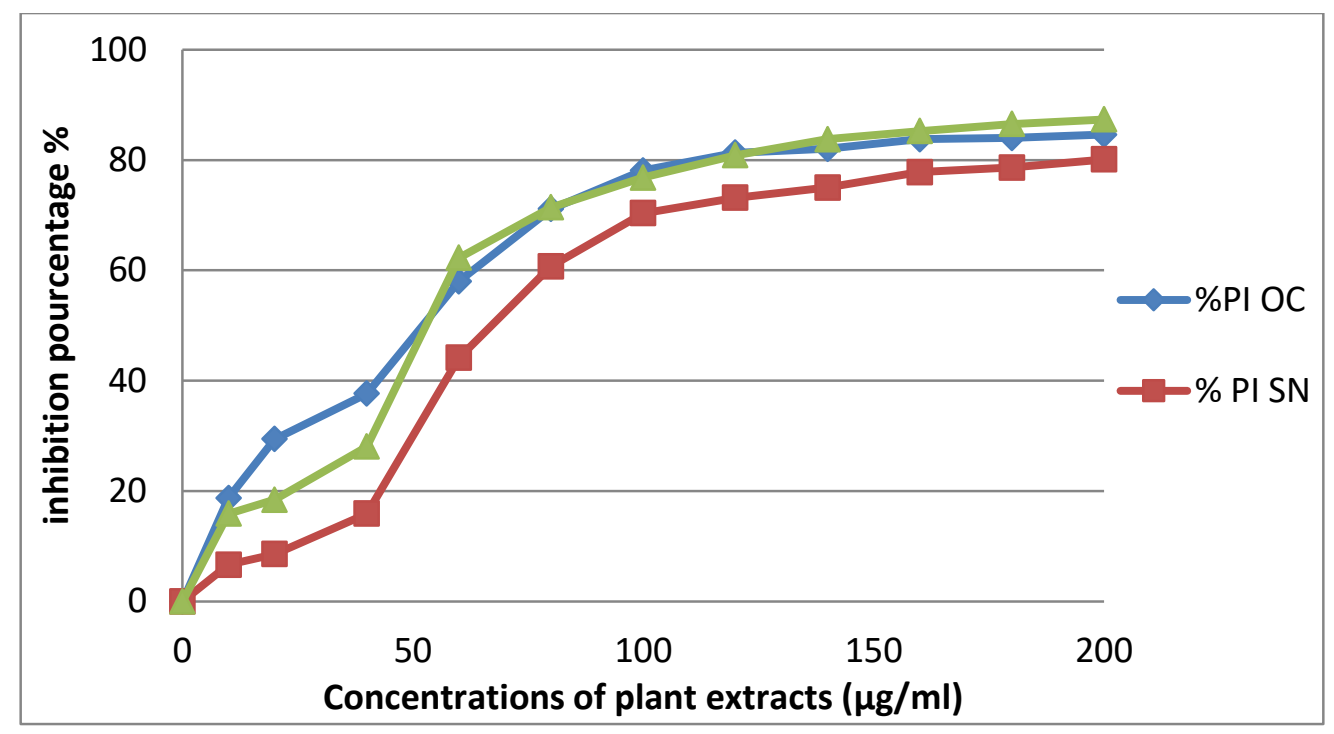

Figure 2. Percentage inhibition of DPPH • as a function of the concentrations of the fractions of Origanum Compactum and Satureja calamintha Nepeta

$\mathrm{PI} \mathrm{OC}=$ percentage of DPPH• inhibition exerted by Origanum compactum PI SN = percentage of DPPH• inhibition exerted Satureja calamintha nepeta PI ACS = percentage of DPPH• inhibition exerted by ascorbic acid

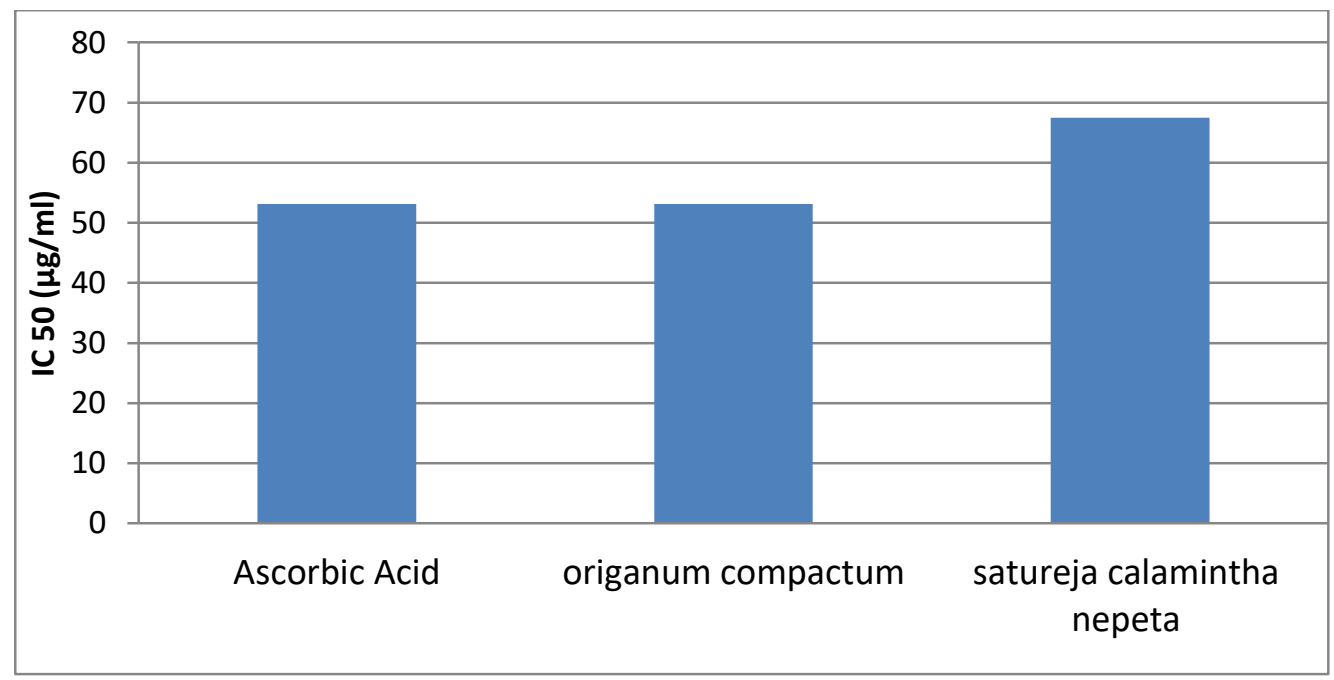

Figure 3. Concentrations of reduction of $50 \%$ of DPPH • 
Origanum Compactum and Satureja calamintha nepeta exhibit a very high antioxidant activity with $\mathrm{IC}_{50}=53.1 \mu \mathrm{g} / \mathrm{ml}$ and $\mathrm{IC}_{50}=67.5 \mu \mathrm{g} / \mathrm{ml}$ respectively. A low $\mathrm{IC}_{50}$ value indicates a strong antioxidant activity. When it comes to comparing the activity of these plants from the family of Lamiaceae with ascorbic acid which has been taken as a standard antioxidant, we note that Satureja calamintha nepeta $\left(\mathrm{IC}_{50}=67.5 \mu \mathrm{g} / \mathrm{ml}\right)$ exerts a lower antioxidant effect than ascorbic acid (IC $50=53.1 \mu \mathrm{g} / \mathrm{ml}$ ). Origanum compactum has the same effect as the standard antioxidant (ascorbic acid). Gonçalves showed that the methanolic extract of origanum vulgare had a stronger DPPH trapping capacity than calamintha nepeta. Other work by ${ }^{26}$ on Origanum glandulosum revealed that its methanol extract had a greater capacity to trap the DPPH - radical compared to essential oils. Our work on satureja calamintha nepeta is coherent with to the work of Ćetković who showed that the highest antioxidant activity was observed for n-butanol extract of Satureja montana L, while at the same concentration, ethyl acetate extract exerted a slightly lower activity ${ }^{5}$.

\subsubsection{FRAP test}

The reducing power of a substance indicates its ability to transfer an electron or a hydrogen atom by reducing $\mathrm{Fe}$ (III) to $\mathrm{Fe}$ (II) in the presence of the $\mathrm{K}_{3} \mathrm{Fe}(\mathrm{CN})_{6}$ complex ${ }^{32}$. The values obtained made it possible to plot the curves shown in the figure below. The standard used as a reference is ascorbic acid. The values obtained made it possible to plot the curves shown in the figure below. The standard used as a reference is ascorbic acid.

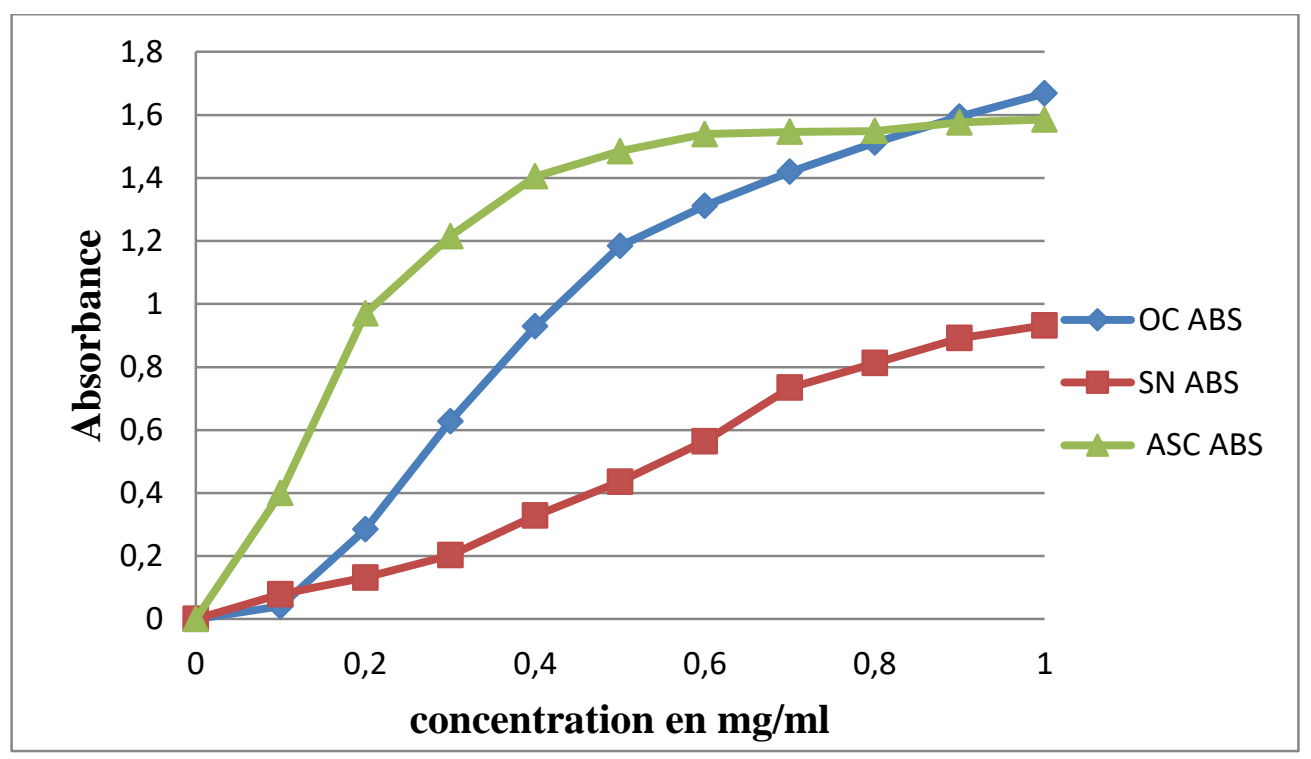

Figure 4. Reducing power of the extracts of the two plants studied, obtained by Maceration

ACS ABS = Absorbance of ascorbic acid

$\mathrm{OC}$ ABS = Absorbance of origanum compactum

$\mathrm{SN} \mathrm{ABS}=$ Absorbance of satureja calamintha nepeta

The results obtained with the maceration method show that the extracts of the two plants tested are characterized by a very pronounced increase in the reduction of iron as a function of the increase in concentration. Figure 4 shows significant differences between the reducing power of the extract of origanum compactum leaves, the aerial part of satureja calamintha nepeta and the positive control (ascorbic-acid).
The methanolic extract of the origanum compactum's leaves exhibited significant antioxidant activity with an optical density of the order of 1.67. On the other hand, with the n-butanolic extract of satureja calamintha népéta, which showed an optical density of the order of 0,93 . The antioxidant capacity of the different extracts is expressed by determining the effective concentration $\left(\mathrm{EC}_{50}\right)$, which corresponds to an absorbance equal to 0.5 to compare their reducing activities.

Table 7. determination of the effective concentration $\left(\mathrm{EC}_{50}\right)$ that corresponds to an absorbance of 0.5 .

\begin{tabular}{|c|c|c|c|}
\hline Espèces & Extract & Absorbance & CE50 mg/ml \\
\hline Origanum compactum & méthanolic & 1,67 & 0,26 \\
\hline Satureja calamintha nepeta & n-butanolic & 0,93 & 0,55 \\
\hline Ascorbic Acid & - & 1,58 & 0,12 \\
\hline
\end{tabular}


Table 7 shows that the extraction by maceration, the leave extracts of origanum compactum and satureja calamintha nepeta cause the reduction of $\mathrm{Fe}^{3+}$ present in the ferricyanide complex of potassium in ferrous iron $\left(\mathrm{Fe}^{2+}\right)$. Their effective concentrations $\left(\mathrm{EC}_{50}\right)$ to reduce $50 \%$ of $\mathrm{Fe}^{3+}$ ions are 0.26 and $0.55 \mathrm{mg} / \mathrm{ml}$ respectively. Origanum compactum has shown a much higher reducing capacity than that found with satureja calamintha nepeta. Still, it remains lower than that of the standard (ascorbic acid) which has a concentration of $0.12 \mathrm{mg} / \mathrm{ml}$. These results have been confirmed by several studies which have shown that origanum vulgara has a great capacity for ferric reduction compared to calamintha nepeta ${ }^{28}$.

\section{Conclusion}

Morocco's geographical location, ecosystems and water resources, make it a country full of plant species endowed with various therapeutic virtues. Origanum compactum and satureja calamintha nepeta, both harvested in the region of Ouazzane were studied, through phytochemical tests, polyphenol extraction and antioxidant activity evaluation. We found that both plants are rich in secondary metabolites, mainly in polyphenols. Their contents ranged from $20.53 \pm 0.008 \mathrm{mg} \mathrm{EGA} / \mathrm{g}$ to $30.8 \pm 0.001 \mathrm{mg} \mathrm{EGA} / \mathrm{g}$ for Origanum compactum. For Satureja calamintha nepeta polyphenol contents ranged from $15.26 \pm 0.00752 \mathrm{mg} \mathrm{EGA} / \mathrm{g}$ to $33.48 \pm 0.0235 \mathrm{mg}$ EGA/g. The assessment of antioxidant activity of origanum compactum and Satureja calamintha nepeta's extracts and fractions by the $\mathrm{DPPH} \cdot$ method showed that both origanum compactum's crude extract and Satureja calamintha nepeta's n-butanol fraction have a very significant antioxidant activity. Inhibitory concentrations $\left(\mathrm{IC}_{50}\right)$ were $53.1 \mu \mathrm{g} / \mathrm{ml}$ and $67.5 \mu \mathrm{g} / \mathrm{ml}$ for Origanum compactum and Satureja calamintha nepeta, respectively. The FRAP test also revealed that the methanolic extract of origanum compactum showed a higher reducing power than that of the n-buthanolic extract of satureja calamintha nepeta but it remains relatively weak than that of ascorbic acid. These potential sources of natural antioxidants could be exploited in food, pharmaceutical and cosmetic preparations.

\section{References}

1. M. Suhaj, Spice antioxidants isolation and their antiradical activity: a review, Journal of Food Composition and Analysis, 2006, 19, 531-537.

2. M. B. Tadhani, V. H. Patel, R. Subhash, In vitro antioxidant activities of Stevia rebaudiana leaves and callus, Journal of Food Composition and Analysis, 2007, 20, 323-329.

3. C. Koechlin-Ramonatxo, Oxygen, oxidative stress and antioxidant supplementation, or another way for nutrition in respiratory diseases, Nutrition Clinique et Métabolique, 2006, 20, 165-177.
4. D. I. Vârban, M. Duda, R. Vârban, S. Muntean, ResearchConcerning the OrganicTechnology for SaturejaHortensis L, Culture.Bulletin UASVM Agriculture, 2009. 66(2), 225- 229.

5. F. Naghibi, M. Mosaddegh, S. M. Motamed, A. Ghorbani, Labiatae Family in folk Medicine in Iran: from ethnobotany to Pharmacology, Iranian Journal of Pharmaceutical Research, 2005, 2, 63-79.

6. A. Belkamel, J. Bammi, A. Belkamel, A. Douira, Etude de la composition chimique de l'huile essentielle d'une endémique Ibéromarocaine:Origanumcompactum (Benth.), J. Anim. Plant Sci., 2013, 19(1), 2880-2887.

7. A. Ordóñez, S. Baldoncini, G. Berioli, G. Chaves, L. Bled, Y. Massuh, C. Liébana, L. Torres, M. Ojeda, Domestication of native aromatic plants, Mol. Med. Chem., 2006, 11, 58-59.

8. M. Hayani, N. T. A. SoroKanigui, Z. Khiya, S. Rarchouf, E. Bruno, C. Sekkat, Z. Haloui, H. Oulhaj, T. Zair, Ethnobotanical study of three medicinal and aromatic species: Satureja nepeta, Myrtus Communis and pistacia lentiscus frommasmouda town (ouazzane province: morocco), International journal of advanced research, 2017, 5(6), 1129-1140.

9. M. Gulluce, M. Sokmen, D. Daferera, G. Agar, H. Ozkan, N. Kartal, In vitro antibacterial, antifungal and antioxidant activities of the essential oil, methanol extracts of herbal parts and callus cultures of Saturejahortensis L, J. Agri. Food. Chem., 2003, 51, 3958-3965.

10. S. Koldas, I. Demirtas, T. Ozen, M. A. Demirci, L. Behçet, Phytochemical screening, anticancer and antioxidant activities of Origanumvulgare L. ssp. viride (Boiss.) Hayek, a plant of traditional usage, J. Sci. Food Agric., 2015, 95, 786-798.

11. A. Bouyahya, J. Abrini, Y. Bakri, N. Dakka, Phytochemical Screening and Evaluation of Antioxidant and AntibacterialActivities of Origanumcompactum Extracts, Phytothérapie, 2017, 15, 379-383.

12. N. Benhamou, A. F. Bekkara, T. K. Panovska, Antioxidant and antimicrobial activities of the Pistacia lentiscus and Pistacia atlantica extracts, African Journal of Pharmacy and Pharmacology, 2008, 2(2), 22-28.

13. I. Oniga, C. Pușcaș, R. Silaghi-Dumitrescu, N. Olah, B. Sevastre, R. Marica, I. Marcus, A. C. Sevastre-Berghian, D. Benedec, C. Elena Pop, D. Hanganu, Origanumvulgare ssp. vulgare: Chemical Composition and Biological Studies, Molecules, 2018, 23(8), 2077.

14. N. Bougandoura, N. Bendimerad, Evaluation de l'activité antioxydante des extraits aqueux et méthanolique de Saturejacalaminthassp.Nepeta

(L.) Briq, Nature \& Technologie, 2012, 9, 14-19.

15. A. Ojeil, N. El Darra, Y. El Hajj, P. Bou Mouncef, T. J. Rizk, R. G. Maroun, Identification 
et Caracterisation de Composes Phenoliques Extraits du Raisin Chateau Ksara, Lebanese Science Journal, 2010, 11, 2(11), 117-131.

16. L. Majhenic, M. S. kerget, Z. Knez, Antioxidant and antimicrobial activity of guarana seedextracts, Food Chemistry, 2007, 104, 12581268.

17. N. Zekri, S. Amalich, A. Boughdad, M. A. El Belghiti, T. Zair, Phytochemical study and insecticidal activity of Mentha pulegium L. oils from Morocco against Sitophilus Oryzae, Mediterranean Journal of Chemistry, 2013, 2(4), 607-619.

18. S. E. El Hassani, A. Driouich, H. Mellouk, B. Bejjany, A. Dani, K. Digua, Extraction of phenolicfromMoroccangrapepomace: Optimization of decoction extraction of phenolic compounds using response surface methodology, Mediterranean Journal of Chemistry, 2019, 7(4), 423-432.

19. A. Djeridane, M. Yous, B. Nadjemi, D. Boutassouna, P. Stocker, N. Vidal, Antioxidant activity of some Algerian medicinal plants extracts containing phenolic compounds, Food Chem., 2006, 97, 654-660.

20. S. Omidpanah, A. Haseli, A. Manayi, Evaluation of antifungal properties of some medicinal plants against aspergillus flavus isolated from contaminated Corn in vitro, Mediterranean Journal of Chemistry, 2015, 3(6), 1093-1099.

21. A. Ouaket, F. Moughaoui, A. Laaraibi, S. Hamdouch, M. Berrada, N. Knouzi, DPPH scavenging activity of some Bis-benzimidazole derivatives, Mediterranean Journal of Chemistry, 2019, 8(2), 103-107.

22. B. S. Maataoui, A. Hmyene, S. Hilali, Activités anti-radicalairesd'extraits de jus de Fruits du figuier de barbarie (Opuntia ficusindica), Lebanese Science Journal, 2006, 7(1), 3-8.

23. S. Gonçalves, E. Moreira, C. Grosso, P. B. Andrade, P. Valentão, A. Romano, Phenolic profile, antioxidant activity and enzyme inhibitory activities of extractsfromaromatic plants used in Mediterranean diet, J. Food Sci. Technol, 2017, 54, 219-227.
24. D. Dobravalskyte, P. R. Venskutonis, T. Talou, Antioxidant properties and essential oil composition of Calaminthagrandiflora L, Food Chemistry, 2012, 135, 1539-1546.

25. G. S. Ćetković, J. Čanadanović-Brunet, S. M. Djilas, V. T. Tumbas, S. L. Markov, D. D. Cetković, Antioxidant Potential, Lipid Peroxidation Inhibition and Antimicrobial Activities of Satureja Montana L. subsp. Kitaibelii Extracts, International Journal of Molecular Sciences, 2007, 8(10), 1013-1027.

26. N. Boizot, J. P. Charpentier, Méthode rapide d'évaluation du contenu en composés phénoliques des organes d'un arbre foustier, Le cahier des techniques de l'Inra, 2006, 79-82.

27. O. Dangles, G. Fargeix, C. Dufour, Oneelectronoxidation of quercetin and quercetin derivatives in protic and non-protic media, J. Chem. Soc., Perkin Trans, 1999, 2, 1387-1395.

28. I. F. F. Benzie, J. J. Strain, The ferric reducing ability of plasma (FRAP) as a measure of antioxidant power: The frapassay, Analytical Biochemistry, 1996, 239, 70-76.

29. A. Podsedek, Natural antioxidantscapacity of Brassicavegetables, LWT-Food Science and Technology, 2007, 40, 1-11.

30. K. N'guessan, B. Kadja, G. N. Zirihi, D. Traoré, L. Aké-assi, Screening phytochimique de quelques plantes médicinales ivoiriennes utilisées en pays Krobou (Agboville, Côte-d'Ivoire), Sciences et Nature, 2009, 6 (1), 1-15.

31. N. Bouhaddouda, S. Aouadi, R. Labiod, Evaluation of Chemical Composition and Biological Activities of Essential Oil and Methanolic Extract of Origanum vulgare L. ssp. glandulosum (Desf.) Ietswaart from Algeria, International Journal of Pharmacognosy and Phytochemical Research, 2016, 8(1), 104-112.

32. M. B. Tadhani, V. H. Patel, R. Subhash, In vitro antioxidantactivities of Stevia rebaudianaleaves and callus, Journal of Food Composition and Analysis, 2007, 20, 323-329. 